\title{
Effect of exposure temperature on deuterium retention and surface blistering of tungsten exposed to sequential nitrogen and deuterium plasma
}

\author{
Shaoyang Qin ${ }^{1,2}$, Liang Gao ${ }^{3}$, Long Cheng ${ }^{1,2}$, Yue Yuan ${ }^{1,2, *}$, Wolfgang Jacob ${ }^{3}$, Guang-Hong Lu $^{1,2}$ \\ Jinliang Wang ${ }^{1}$ \\ ${ }^{1}$ School of Physics \& Nuclear Energy Engineering, Beihang University, Beijing, 100191, China \\ ${ }^{2}$ Beijing Key Laboratory of Advanced Nuclear Materials and Physics, Beihang University, Beijing, \\ 100191, China \\ ${ }^{3}$ Max-Planck-Institut für Plasmaphysik, Boltzmannstraße 2, D-85748 Garching, Germany
}

Corresponding author E-mail: yueyuan@buaa.edu.cn

\begin{abstract}
Rolled tungsten (W) was sequentially exposed to nitrogen (N) and deuterium (D) plasma at different surface temperatures to investigate the influence of $\mathrm{N}$ pre-irradiation on $\mathrm{D}$ retention and surface blistering of W. Surface imaging revealed that significant amounts of blisters are formed after D exposure at 230 and $370 \mathrm{~K}$. However, no blisters were found in the case of $520 \mathrm{~K} \mathrm{D}$ exposure. In addition, $\mathrm{N}$ pre-irradiation increases the areal density of blisters, in particular that of small blisters. This effect becomes more significant for $500 \mathrm{~K} \mathrm{~N}$ exposure compared with $300 \mathrm{~K} \mathrm{~N}$ exposure. D depth profiles show that $\mathrm{N}$ pre-irradiation leads to an increase of the $\mathrm{D}$ concentration in the near surface. Thermal desorption spectra show that only one main desorption peak appears for the case of 230/520 K, while two peaks are found for 370 K D exposure. Though N pre-irradiation does not change the deuterium desorption peak positions, it slightly changes the total $\mathrm{D}$ retention. These phenomena indicate a temperature dependence of the effect of $\mathrm{N}$ pre-irradiation on the $\mathrm{D}$ behavior in $\mathrm{W}$.
\end{abstract}

Keywords: nitrogen, tungsten, deuterium retention, surface blistering

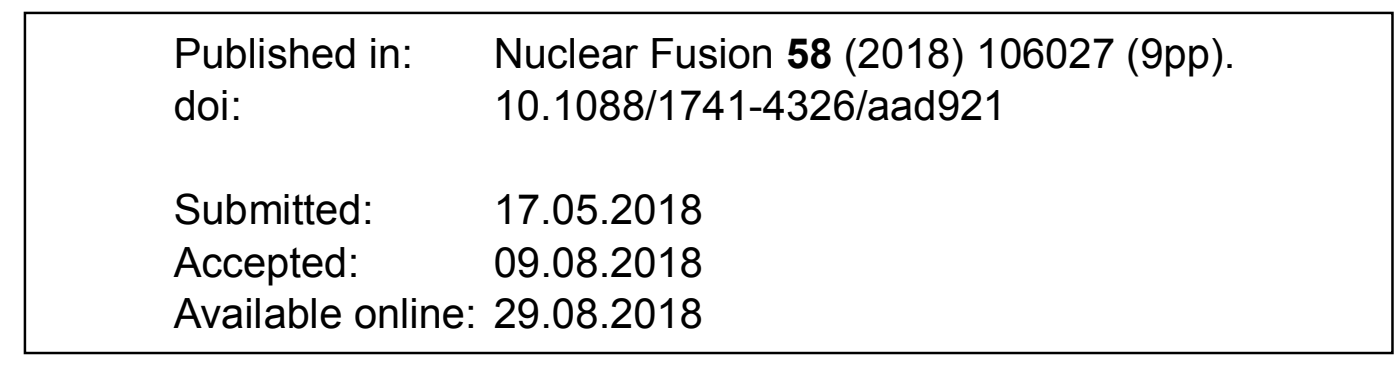




\section{Introduction}

Tungsten (W) is a candidate plasma-facing material for future fusion devices [1]. It has many advantages such as high melting point and thermal conductivity as well as low sputtering yield and hydrogen inventory [1][2]. A full $\mathrm{W}$ divertor will be used in ITER from the beginning of operations [3]. W divertor armor will be exposed to high heat fluxes, which can result in severe surface damage, like surface roughening, melting or cracking [3]. Impurity seeding, such as nitrogen $(\mathrm{N})$ or noble gases, for radiative power removal is mandatory for high-power operations to mitigate the power loads and to reduce the damage of $\mathrm{W}$ armor [4].

Nitrogen has favorable radiation properties and it can enhance plasma performance via seeding into the divertor region [5]. However, the introduction of $\mathrm{N}$ leads to issues of $\mathrm{N}$ legacy and the formation of volatile compounds [6]. W:N layers are found on the tiles of TEXTOR after $\mathrm{N}$ seeding experiments [7]. The $\mathrm{W}: \mathrm{N}$ layers have different phases, e.g., $\mathrm{WN}$ or $\mathrm{W}_{2} \mathrm{~N}$ [8], and it was found that the N/W ratio decreases with increasing temperature [9][10]. It has been shown that W:N layers are thermally stable up to about $800 \mathrm{~K}$ and decomposition starts at around $830 \mathrm{~K}[11]$.

As a plasma-facing material, $\mathrm{W}$ will be subjected to intense fluxes of low-energy deuterium (D) and tritium particles as well. The W:N layers are supposed to affect the interaction of D plasma and $\mathrm{W}$ surfaces. An experimental study indicated that $\mathrm{N}$-enriched layers at the $\mathrm{W}$ surface can act as a diffusion barrier for the re-emission of implanted hydrogen [12]. A theoretical study also shows $\mathrm{N}$ atoms trapped in a vacancy significantly reduce the hydrogen effective diffusivity [13].

$\mathrm{D}$ retention in $\mathrm{W}$ depends in a complicated manner on a variety of exposure and material parameters such as, e.g., ion energy, ion flux, and ion fluence, as well as sample temperature, microstructure, impurity concentration, and intrinsic defect concentration to name the most important ones. For details the reader is referred to recent reviews by Skinner et al. [14], Roth and Schmid [15], and Tanabe [16]. In particular the behavior of $\mathrm{W}$ exposed to low-energy and high-flux D plasma has been widely investigated with respect to surface blistering and D retention. At low temperatures small low-dome blisters are sparsely formed on the W surface, and both large blisters and small blisters appear if the temperature increases to $500 \mathrm{~K}$. With increasing temperature, the blisters become much sparser and finally disappear at above $1000 \mathrm{~K}$ [17][18]. In general, D retention increases with exposure temperature, reaching a maximum value at about $500 \mathrm{~K}$, and then decreases at higher temperatures [18][19]. As mentioned, the incident plasma flux also affects surface blistering and $\mathrm{D}$ retention. It was reported that smaller blisters are more likely to be formed under high-flux D plasma exposure [20]. A detailed comparison of high- and low-flux exposures for otherwise comparable conditions was recently published by Balden et al. [21].

In this context, it is important to study the effect of $\mathrm{N}$ irradiation on the $\mathrm{D}$ behavior in $\mathrm{W}$ and taking the influence of exposure temperature into account. Therefore, in this work we expose $\mathrm{W}$ consecutively to $\mathrm{N}$ and $\mathrm{D}$ plasma and investigate the surface blistering and $\mathrm{D}$ retention at different temperatures. 


\section{Experiments}

W samples used in the present work were cut from a hot-rolled sheet $(0.8 \mathrm{~mm}$ thick, PLANSEE, $99.97 \%$ purity). The dimensions of the samples were $12 \times 15 \times 0.8 \mathrm{~mm}^{3}$. They were mechanically polished to a mirror-finish and subsequently ultrasonically cleaned in isopropanol. Then they were annealed in vacuum $\left(<10^{-6} \mathrm{~Pa}\right)$ for $1 \mathrm{~h}$ at $1200 \mathrm{~K}$ for hydrogen degassing, surface stress release, and oxide layer removal.

A characteristic surface of a W sample after preparation is shown in Fig. 1. The grains are visible in the scanning electron microscopy (SEM) image. The average grain size is $\sim 6 \mu \mathrm{m}$. According to producer specifications this material is nominally identical to the $\mathrm{W}$ material used in many prior investigations in IPP Garching [22][23]. Similar microstructure has been shown in [23]. However, the average grain size of the hot-rolled $\mathrm{W}$ sheet in the present work is a little bit larger than that used in [23].

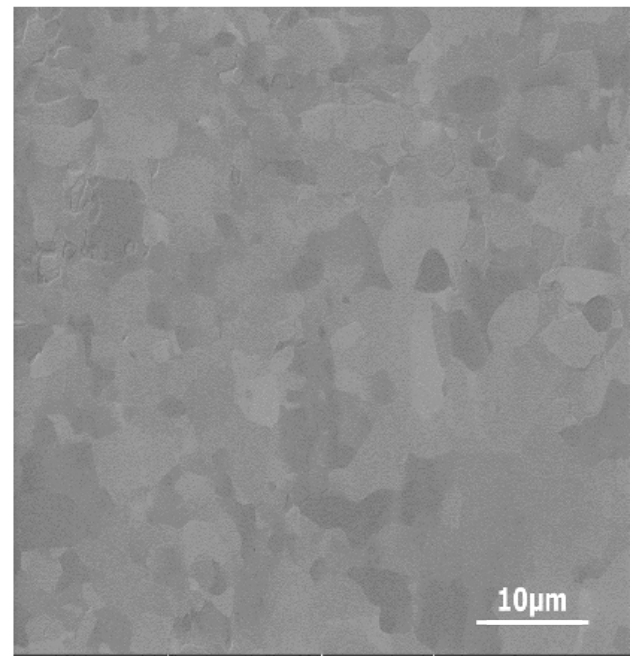

Fig. 1 Characteristic SEM image of an as-prepared W sample.

$\mathrm{N}$ and D plasma implantation were performed in a low-pressure steady-state electron cyclotron resonance (ECR) plasma chamber named 'PlaQ' [24]. To allow for a burn-in time of the plasma without exposing the sample to the beam a shutter between the aperture separating the plasma region from the sample was closed for about $10 \mathrm{~min}$. To stabilize the sample holder temperature between $230 \mathrm{~K}$ and $520 \mathrm{~K}$, two open circuit thermostats one with silicon oil and the other with ethanol were used.

Six samples divided into two groups were irradiated by $\mathrm{N}$ plasma at 300 and $500 \mathrm{~K}$, respectively. The working pressure of $\mathrm{N}$ plasma was $0.25 \mathrm{~Pa}$ and a gas flow of $50 \mathrm{sccm} \mathrm{N} \mathrm{N}_{2}$ gas was applied. Under these conditions $\mathrm{N}^{2+}$ was the dominant ion specie $(\approx 80-90 \%)$ in the ion flux with minor contributions from $\mathrm{N}^{3+}$ and $\mathrm{N}^{+}$ions ( $\approx 5-10 \%$ each) [25]. The ion flux of the main species was about $4 \times 10^{18} \mathrm{~N}^{2+} \mathrm{m}^{-2} \mathrm{~s}^{-1}$ [25]. The $\mathrm{N}$ plasma exposure lasted for $30 \mathrm{~min}$ and the total $\mathrm{N}$ fluence was about $1.5 \times 10^{22} \mathrm{~N} \mathrm{~m}^{-2}$. For $\mathrm{D}$ plasma exposure, nine samples including the six $\mathrm{N}$-irradiated samples and another three blank W samples were prepared. These nine samples were divided into three groups and each group included one sample with $\mathrm{N}$ irradiation at $300 \mathrm{~K}$, one sample with $\mathrm{N}$ irradiation at $500 \mathrm{~K}$ and a blank sample without $\mathrm{N}$ 
irradiation. The three groups were each exposed to D plasma for 167 min with a fluence of $1.0 \times 10^{24} \mathrm{D} \mathrm{m}^{-2}$ at $230 \mathrm{~K}, 370 \mathrm{~K}$ and $520 \mathrm{~K}$ respectively. A pressure of $1.0 \mathrm{~Pa}$ was used for the $\mathrm{D}$ exposures. For these plasma parameters the $\mathrm{D}$ ion flux consists predominantly of $\mathrm{D}^{3+}$ ions (94\%) with minor contributions of $\mathrm{D}^{2+}(3 \%)$ and $\mathrm{D}^{+}(3 \%)$ [24]. For $\mathrm{N}$ and $\mathrm{D}$ plasma exposures a DC target bias of $-200 \mathrm{~V}$ was applied. With a plasma potential of $15 \mathrm{eV}$ the maximum ion energy was $215 \mathrm{eV}$ and the dominant energy per atom was $72 \mathrm{eV}$ per $\mathrm{D}$ and $108 \mathrm{eV}$ per $\mathrm{N}$ for the respective dominant ion species.

Surface modifications were analyzed by an optical differential interference contrast (DIC) microscope (Olympus LEXT OLS4000). The centers of the exposed regions were observed. For determining the blister-size distributions, the blisters identified in the optical DIC images were manually marked and their size was estimated by assuming a circular shape with an equivalent area to each blister.

The sub-surface morphology was observed by SEM after cross-sectioning with a focused ion beam (TESCAN LYRA3 FEG-SEM/FIB). To reduce artefacts due to the FIB cutting process, a Pt-C film was deposited onto the investigated surface in situ prior to the FIB cross-sectioning. The observation of FIB cross-sections was made at a tilt angle of $55^{\circ}$.

The $\mathrm{D}$ depth profiles in the $\mathrm{W}$ samples were measured by nuclear reaction analysis using $\mathrm{D}\left({ }^{3} \mathrm{He}, \mathrm{p}\right){ }^{4} \mathrm{He}$ reaction. An analyzing beam of ${ }^{3} \mathrm{He}$ ions with energies varying from 0.5 to 4.5 $\mathrm{MeV}$ was used, which allowed us to determine the retained $\mathrm{D}$ concentration up to a depth of $8 \mu \mathrm{m}$. The $\mathrm{D}$ depth profiles were determined by deconvolving the acquired proton spectra from the ${ }^{3} \mathrm{He}$ NRA measurements using the NRADC data evaluation program [26]. The sensitivity limit of the used NRA set-up is about $10^{-5} \mathrm{D} / \mathrm{W}$.

D desorption behavior was examined by thermal desorption spectroscopy (TDS) in Beihang University. The base pressure of the TDS chamber was better than $5 \times 10^{-5} \mathrm{~Pa}$. The sample was located $\sim 5 \mathrm{~mm}$ above a $\mathrm{W}$ rod heater and was heated up to $1423 \mathrm{~K}$ with a ramping rate of $1 \mathrm{~K} / \mathrm{s}$. The sample temperature was measured and monitored by a W-25 Re thermocouple, connected to the bottom of the target sample. Signals of mass 3 (HD), mass 4 $\left(\mathrm{D}_{2}\right)$, mass 19 (HDO) and mass $20\left(\mathrm{D}_{2} \mathrm{O}\right)$ were recorded by a quadruple mass spectrometer (MKS Microvision Plus). The signal of mass 4 was calibrated by a $\mathrm{D}_{2}$ calibration leak and the signal of mass 2 was calibrated by a $\mathrm{H}_{2}$ calibration leak. Mass 3 was calibrated by averaging the calibration of mass 2 and mass 4 signals. The contribution of deuterated water to $\mathrm{D}$ release was estimated from the measured mass 19 and 20 signals applying the published sensitivity factor for water. The partial pressure of HDO, as well as that of $\mathrm{D}_{2} \mathrm{O}$, has the same order of magnitude for all investigated targets before and during the temperature ramping process. Therefore, the desorbed $\mathrm{D}$ in form of deuterated water was not taken into account. The released D amount from the samples was calculated from the $\mathrm{HD}$ and $\mathrm{D}_{2}$ signals and the contribution of HD to the D release was below $10 \%$. The uncertainty of the TDS-determined $\mathrm{D}$ amounts is dominated by the stability of the detector in the mass spectrometer and by contributions to the D release in form of $\mathrm{HDO}$ and $\mathrm{D}_{2} \mathrm{O}$. The overall uncertainty is estimated to be about $7 \%$. 


\section{Results}

\subsection{Surface blistering}

Optical DIC micrographs of the $\mathrm{W}$ targets after being sequentially exposed to $\mathrm{N}$ plasma and D plasma at different temperatures are shown in Fig. 2. The sub-figures are arranged in three rows for different D plasma exposure temperature, and the columns correspond to without or with $\mathrm{N}$ pre-irradiation at different temperatures. Blistering is noticeable for $370 \mathrm{~K}$ $\mathrm{D}$ exposure and mitigated in the case of $230 \mathrm{~K}$, while it is completely suppressed at $520 \mathrm{~K}$. For the case of $520 \mathrm{~K} \mathrm{D}$ exposure, it should be noted that we have scanned the whole sample surface and confirmed that no blisters can be found. Similar results have been reported in [27]. It is not easy to determine the reason since besides the sample temperature a lot of factors including the material grades and the plasma parameters could also affect the blistering features [20][28]. However, it seems that for the here used material and exposure conditions, there is a critical temperature for blister formation. To clarify this issue, further investigations are necessary.

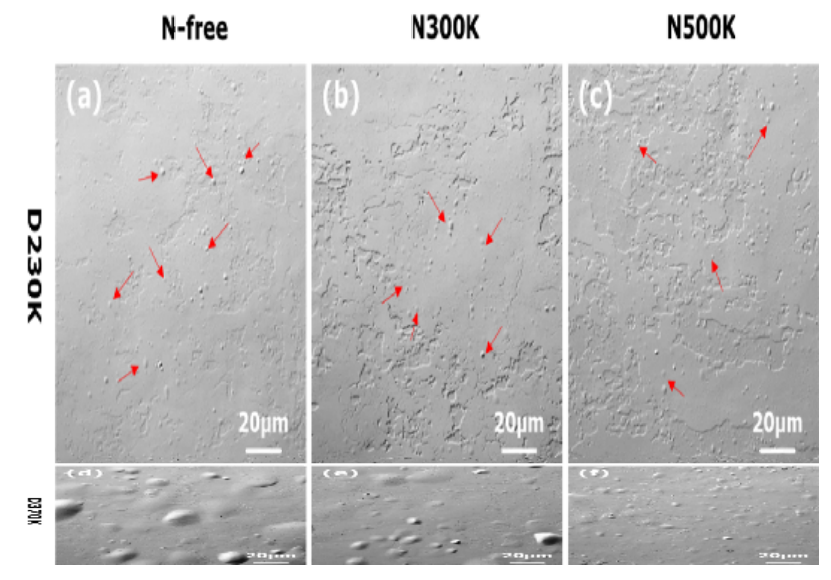

Fig. 2. Optical DIC micrographs of W samples after D exposure without or with N pre-implantation. A number of small blisters are marked by red arrows. 
For $230 / 370 \mathrm{~K} \mathrm{D}$ exposure, $\mathrm{N}$ pre-irradiation changes the D-induced blistering to some extent. In order to further study the $\mathrm{N}$ pre-irradiation effect on blistering, histograms of the determined blister-size distributions for the samples with $\mathrm{D}$ exposures at 230 and $370 \mathrm{~K}$ are shown in Fig. 3. Log-normal distributions were used to fit the blister size distributions. These fits are shown as solid lines in Figs. 3(a) and 3(b). The statistical data of the blister-size distributions are summarized in Table 1.
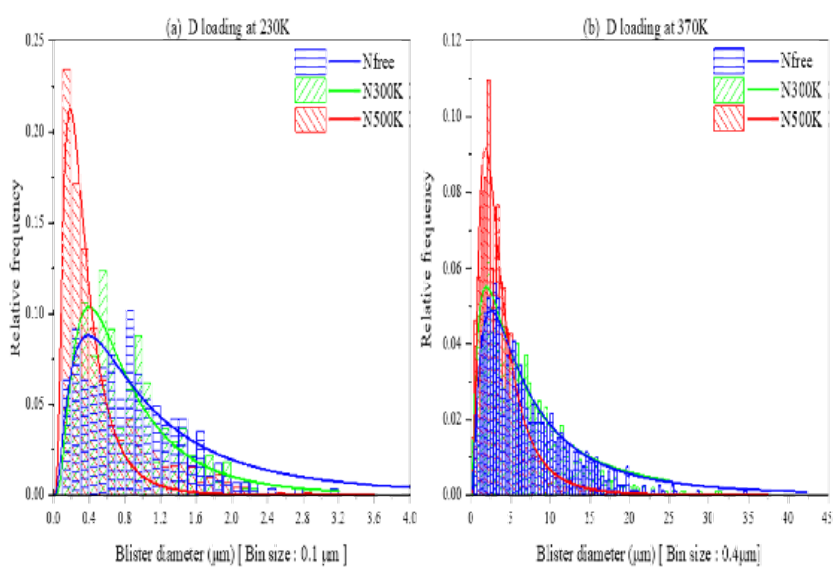

Fig. 3. Blister-size distributions for rolled $\mathrm{W}$ exposed to D plasma at $230 \mathrm{~K}$ (a) and $370 \mathrm{~K}$ (b). N300K and $\mathrm{N} 500 \mathrm{~K}$ represent the samples with different $\mathrm{N}$ pre-irradiation temperature at 300 and $500 \mathrm{~K}$. Nfree stands for the sample without $\mathrm{N}$ pre-irradiation. The solid lines indicate log-normal distributions.

Table 1 The statistical data of the blister-size distributions for samples exposed to D plasma at $230 \mathrm{~K}$ and $370 \mathrm{~K}$.

\begin{tabular}{ccccccc}
\hline \multirow{2}{*}{ Samples } & \multicolumn{3}{c}{ D loading at $230 \mathrm{~K}$} & \multicolumn{3}{c}{ D loading at 370 K } \\
& Nfree & N300K & N500K & Nfree & N300K & N500K \\
\hline $\begin{array}{c}\text { Average blister size }[\mu \mathrm{m}] \\
\text { Most probable blister size } \\
{[\mu \mathrm{m}]}\end{array}$ & 0.9 & 0.8 & 0.5 & 7.0 & 6.2 & 3.7 \\
$\begin{array}{c}\text { Areal density } \\
{\left[10^{3} \text { blister } / \mathrm{mm}^{2}\right]}\end{array}$ & 0.4 & 0.4 & 0.2 & 2.4 & 2.0 & 1.8 \\
Evaluated area $\left[\mu \mathrm{m}^{2}\right]$ & 16.5 & 18.0 & 42.5 & 11.6 & 16.0 & 31.0 \\
\hline
\end{tabular}

In the Nfree case of $230 \mathrm{~K} \mathrm{D}$ exposure, the surface is covered by a large number of small blisters with a diameter $<3.2 \mu \mathrm{m}$ (see Fig. 3(a)). The average blister size is $0.9 \mu \mathrm{m}$ (Tab. 1). We selected a typical blister on its top for FIB cutting as shown in Fig. 4(a). We can see a narrow cavity along a grain boundary below the blister in a depth of about $150 \mathrm{~nm}$. For the samples with $\mathrm{N}$ pre-irradiation, the surface is densely covered by nanometer-sized blisters and the average sizes are $0.8 \mu \mathrm{m}$ and $0.5 \mu \mathrm{m}$ for $\mathrm{N} 300 \mathrm{~K}$ and $\mathrm{N} 500 \mathrm{~K}$, respectively (Tab. 1). The blister size distributions (Figs. 3(a) and (b)) show that smaller-size blisters contribute to a higher fraction for samples with $\mathrm{N}$ pre-irradiation, especially for N500K. However, the areal density of blister is slightly increased by $300 \mathrm{~K} \mathrm{~N}$ pre-irradiation and significantly increased by a factor of up to 3 in the case of N500K. 


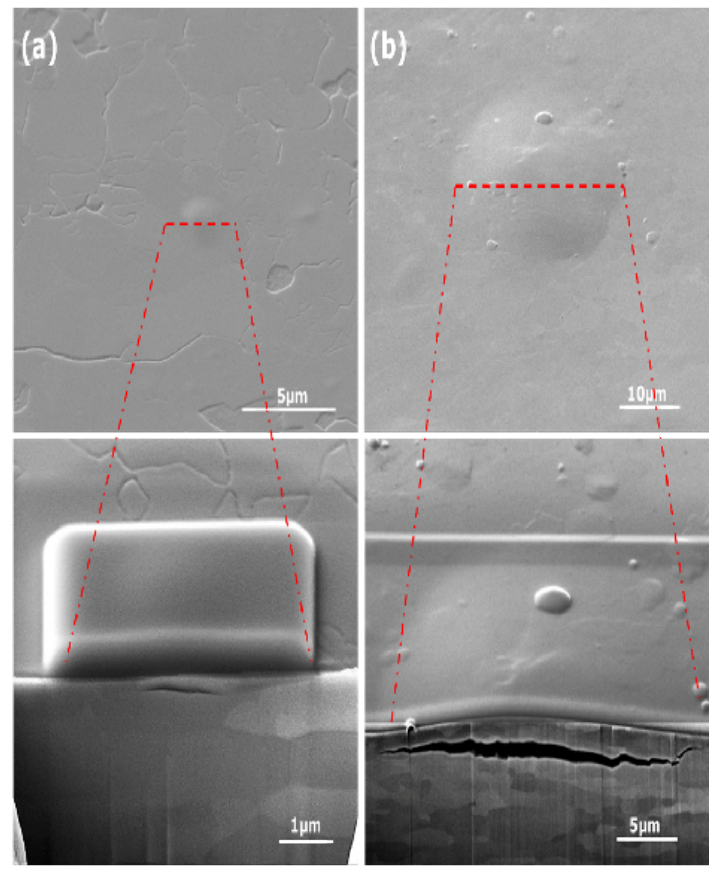

Fig. 4. SEM images of cross-sections of $\mathrm{W}$ samples. The position of the cut is labeled by the red dash line. (a) a small blister on the Nfree_D230 K sample, (b) a large blister on the N300 K_D370 K sample.

For the three groups of exposures corresponding to $370 \mathrm{~K} \mathrm{D}$ exposure, the blisters are much larger, but the areal density is lower compared with $230 \mathrm{~K} \mathrm{D}$ exposure. In the case of Nfree, the maximum size is $>30 \mu \mathrm{m}$ and the average size is about $7 \mu \mathrm{m}$. It is worth mentioning that this average blister size is larger than the mean grain size of the rolled $\mathrm{W}$ (see Fig. 1). We selected a typical large blister with some small blisters on its top for FIB cutting as shown in Fig. 4(b). The big cavity shown in Fig. 4(b) which locates at $3.5 \mu \mathrm{m}$ depth is well visible and extends over several grains. From Fig. 3(b) we can see that most blister sizes are in the range of $1-10 \mu \mathrm{m}$. The difference of the blister-size distributions for the $\mathrm{N} 300 \mathrm{~K}$ and Nfree samples is not very significant, while the N300K sample has a higher ratio of small blisters $(<5 \mu \mathrm{m})$ than the Nfree sample. In addition, the average blister size of N500K is $3.7 \mu \mathrm{m}$ which is much smaller than for the other two samples, mainly because the ratio of the small blisters $(<5 \mu \mathrm{m})$ is much higher than the other two samples.

From the above, it is indicated that the features of surface blistering strongly depend on the exposure temperature and $\mathrm{N}$ pre-irradiation. With $\mathrm{N}$ pre-irradiation, the formation of smaller-size blisters is enhanced, which results in a higher ratio of small blister and a lower average blister size, and this effect is more significant for $500 \mathrm{~K} \mathrm{~N}$ pre-irradiation than for $300 \mathrm{~K}$.

\subsection{Deuterium depth profiles}

Fig. 5 shows the deuterium depth distributions determined by using NRADC for the deconvolution of the acquired proton spectra. For these samples, the $\mathrm{D} / \mathrm{W}$ ratio reaches a maximum of about $1 \times 10^{-2} \mathrm{D} / \mathrm{W}$ at the top surface $(<30 \mathrm{~nm})$. It should be noted that, this ratio in this D-oversaturated layer in the top surface is actually the averaged value by NRADC for the best depth resolution with the present NRA setup. More details can be found in Ref. [29].

As shown in Figs. 5(a) and (b) after D exposure at $230 \mathrm{~K}$, the D/W ratio in the case of 
Nfree is $1.5 \times 10^{-2} \mathrm{D} / \mathrm{W}$ in the top surface $(<30 \mathrm{~nm})$ and then decreases to $3 \times 10^{-3} \mathrm{D} / \mathrm{W}$. In the depth of $125 \mathrm{~nm}$, it drops to $5.3 \times 10^{-4} \mathrm{D} / \mathrm{W}$ and further decreases to $1.9 \times 10^{-5} \mathrm{D} / \mathrm{W}$ in depths larger than $610 \mathrm{~nm}$. The $\mathrm{D} / \mathrm{W}$ ratio with $\mathrm{N}$ pre-irradiation is similar to the Nfree case. For $\mathrm{N} 300 \mathrm{~K}$, it is $7 \times 10^{-3} \mathrm{D} / \mathrm{W}$ in the top surface and then decreases to $5.3 \times 10^{-4} \mathrm{D} / \mathrm{W}$ in the depth up to $125 \mathrm{~nm}$. It drops to $1.9 \times 10^{-5} \mathrm{D} / \mathrm{W}$ in for depths larger than $610 \mathrm{~nm}$. In the case of N500K, it is also $7 \times 10^{-3} \mathrm{D} / \mathrm{W}$ in the top surface and then decreases to $2 \times 10^{-3} \mathrm{D} / \mathrm{W}$ in the depth of $125 \mathrm{~nm}$. It drops to $2.4 \times 10^{-5} \mathrm{D} / \mathrm{W}$ for depths larger than $410 \mathrm{~nm}$. Most of the trapped $\mathrm{D}$ atoms concentrate in the near surface region $(<400 \mathrm{~nm}$ ), and the FIB cross-section (Fig. 4) shows that the cavities corresponding to small blisters are also within this depth. We have calculated the total retained $\mathrm{D}$ amount within $400 \mathrm{~nm}$ from the depth profiles. The D amount for N500K is about $1.4 \times 10^{19} \mathrm{D} \mathrm{m}^{-2}$ which is the highest in these three samples. $\mathrm{N} 300 \mathrm{~K}$ and Nfree are almost the same which are about $1.0 \times 10^{19} \mathrm{D} \mathrm{m}^{-2}$.

In Fig. 5(c) and (d) after D exposure at $370 \mathrm{~K}$ the $\mathrm{D} / \mathrm{W}$ ratio in the case of Nfree is $9 \times 10^{-3} \mathrm{D} / \mathrm{W}$ in the top surface and then drops to $1.4 \times 10^{-3} \mathrm{D} / \mathrm{W}$ at the depth of $30 \mathrm{~nm}$. For depths larger than $1.2 \mu \mathrm{m}$, it increases to $2 \times 10^{-3} \mathrm{D} / \mathrm{W}$ and then to $3 \times 10^{-3} \mathrm{D} / \mathrm{W}$ at the depth of $2.5 \mu \mathrm{m}$. For depths larger than $3.5 \mu \mathrm{m}$, it decreases to $1 \times 10^{-3} \mathrm{D} / \mathrm{W}$ and drops to $2.7 \times 10^{-4} \mathrm{D} / \mathrm{W}$ in depth of $5.2 \mu \mathrm{m}$. For the cases of $\mathrm{N}$ pre-irradiation, within the depth of $820 \mathrm{~nm}$, the $\mathrm{D} / \mathrm{W}$ ratio is close to that of Nfree but still a little bit higher. In the depth between $820 \mathrm{~nm}$ and 2.5 $\mu \mathrm{m}$, it is about $2 \times 10^{-3} \mathrm{D} / \mathrm{W}$ which is higher than for the Nfree case.

According to the results present above, the blister size is closely related to the depth where the cavity is located which is in agreement with findings reported by Bauer et al. [30]. This region also corresponds to a high local D concentration. By comparing Figs. 5(b) and (d), we can find that the $\mathrm{D}$ concentration in the depth of several micrometers is significant higher in the case of D370K than D230K. That probably explains the resulting larger average blister size for D370K.

For D520K (Figs. 5(e) and (f)), in the case of Nfree most of the D atoms concentrate within $\sim 30 \mathrm{~nm}\left(>1 \times 10^{-2} \mathrm{D} / \mathrm{W}\right)$. Then it drops sharply to $3 \times 10^{-5} \mathrm{D} / \mathrm{W}$. The two samples with $\mathrm{N}$ pre-irradiation at 300 and $500 \mathrm{~K}$ show similar $\mathrm{D}$ depth profiles. Within $130 \mathrm{~nm}$ the $\mathrm{D} / \mathrm{W}$ ratio is higher than about $1 \times 10^{-3} \mathrm{D} / \mathrm{W}$. After this depth it drops to about $4 \times 10^{-5} \mathrm{D} / \mathrm{W}$. It indicates that the $\mathrm{D}$ atoms just concentrate within the depth of about $100 \mathrm{~nm}$ after D exposure at $520 \mathrm{~K}$. 

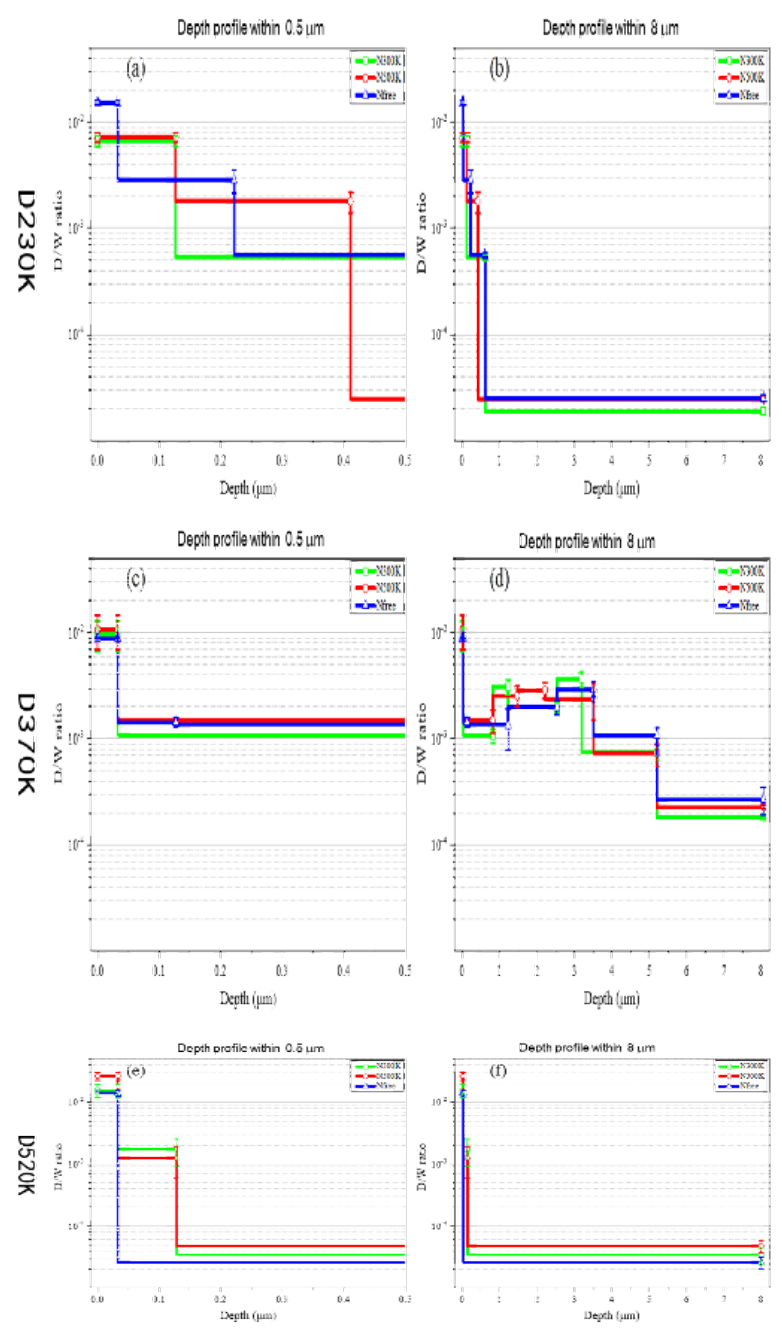

Fig. 5. Deuterium depth profiles in $\mathrm{W}$ with or without $\mathrm{N}$ pre-irradiation followed by $\mathrm{D}$ plasma exposure at different temperatures. (a)(b) D exposure at $230 \mathrm{~K}$, (c)(d) D exposure at $370 \mathrm{~K}$, (e)(f) D exposure at $520 \mathrm{~K}$.

\subsection{Deuterium desorption}

The $\mathrm{D}_{2}$ desorption spectra for the samples are shown in Fig. 6. The samples exposed to $\mathrm{D}$ plasma at $230 \mathrm{~K}$ have only one desorption peak at $460 \mathrm{~K}$ as shown in Fig. 6(a). The peak widths for the 3 different cases are comparable, with varying peak intensity by up to $25 \%$. The samples exposed to D plasma at $370 \mathrm{~K}$ (Fig. 6(b)) show a dominant desorption peak at $590 \mathrm{~K}$ and a shoulder peak at a lower temperature of about $470 \mathrm{~K}$. Similarly, as for D230K (Fig. 6(a)), the shapes of the peaks for the three samples are almost identical. For the samples exposed to D plasma at $520 \mathrm{~K}$ the TDS spectra show only one peak located at 590-610 K (Fig 6(c)) and the intensities of the peaks with $\mathrm{N}$ pre-irradiation are two times that of the Nfree case. In contrast to the other two cases, for Nfree case the peak shape differs slightly, and there seems to be a variation of the peak position of up to about $20 \mathrm{~K}$. It is worth to mention 
that the reproducibility of the temperature in our TDS set-up has an uncertainty of about 10-20 K. Taking this into consideration, we can classify all TDS spectra shown in Fig. 6 into two peaks: one at $470 \mathrm{~K}$ and the other at about $600 \mathrm{~K}$. It is indicated that $\mathrm{N}$ pre-irradiation does not change the positions of $\mathrm{D}$ desorption peak but the intensities.

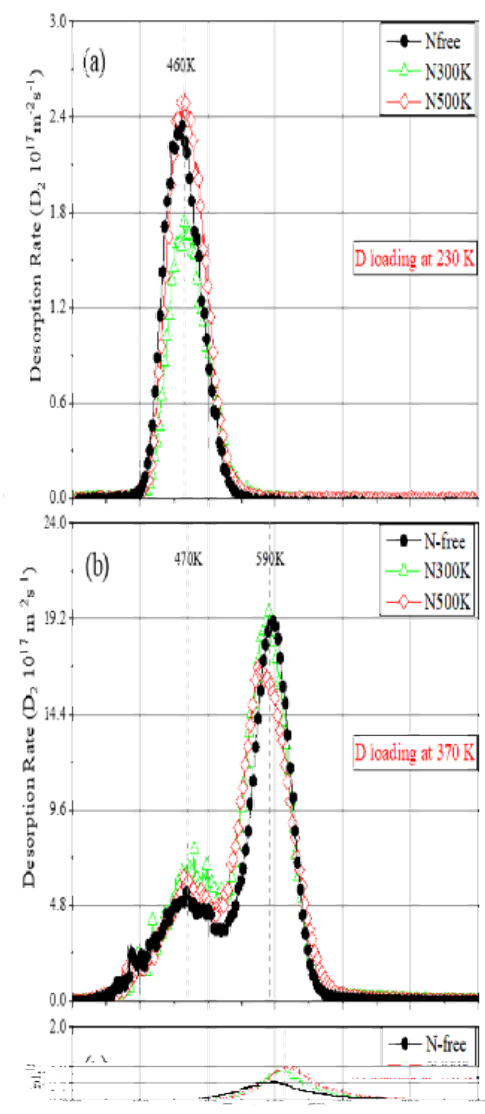

Fig. 6. $\mathrm{D}_{2}$ desorption profiles for $\mathrm{W}$ samples exposed to $\mathrm{D}$ at different temperatures with or without $\mathrm{N}$ pre-implantation.

The total released $\mathrm{D}$ amounts considering contributions from both $\mathrm{D}_{2}$ and $\mathrm{HD}$ are shown in Fig. 7. The samples exposed to D at $370 \mathrm{~K}$ show the largest released D amounts which is about 10 times that of D230K and D520K. After D exposure at $370 \mathrm{~K}$, the D releases of the samples with $\mathrm{N}$ pre-irradiation are about $10 \%$ higher than the Nfree case. After D plasma implantation at $520 \mathrm{~K}, \mathrm{~N}$ pre-irradiation also enhances the accumulation of $\mathrm{D}$ in $\mathrm{W}$ by a factor of up to 2 compared with the $\mathrm{N}$-free case. 


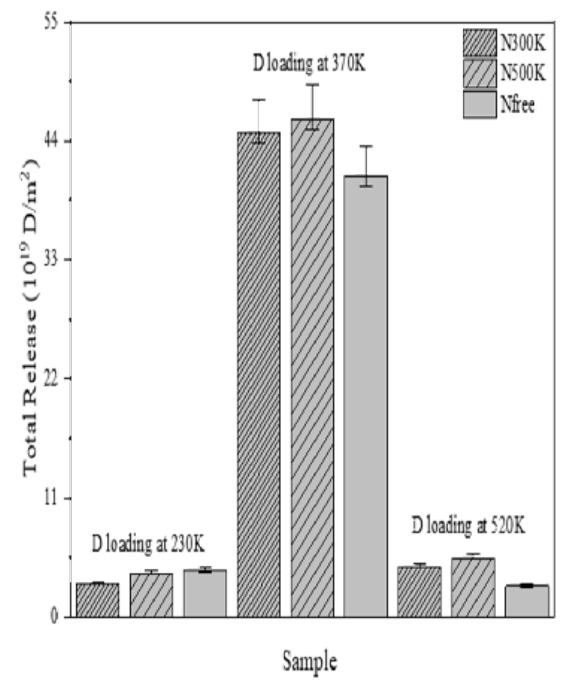

Fig. 7. Total amount of $\mathrm{D}$ released from $\mathrm{W}$ samples exposed to $\mathrm{D}$ at different temperatures with or without $\mathrm{N}$ pre-implantation as determined by TDS.

\section{Discussion}

Based on a comparison of the surface morphology and D retention of rolled $\mathrm{W}$ sequentially exposed to $\mathrm{N}$ and $\mathrm{D}$ plasma at different temperatures, we can see that the $\mathrm{D}$ exposure temperature plays an important role, and $\mathrm{N}$ pre-irradiation also changes the $\mathrm{D}$ behavior in $\mathrm{W}$ which exhibits a temperature dependence as well.

Blistering and D retention are most noticeable at D370K, and they change with $\mathrm{N}$ pre-irradiation at different temperatures. With $\mathrm{N}$ pre-irradiation, the $\mathrm{D}$ concentration within the depth of $2.5 \mu \mathrm{m}$ is increased (Fig. 5 (d)). It is concluded that $\mathrm{N}$ pre-irradiation plays an important role on $\mathrm{D}$ diffusion and transport in the near surface of $\mathrm{W}$.

It has been reported that a N-containing surface layer [25][27][31] could act as a barrier for D diffusion in $\mathrm{W}$ [11][12]. According to [32], with the experimental conditions used in our work, the mean implantation range of $\mathrm{N}$ ions in $\mathrm{W}$ is about $1.2 \mathrm{~nm}$. Gao et al. [33] used TRIDYN [34] to calculate the D penetration depths in the W-N layer for D atom with different energy. The results showed that the penetration depths of $\mathrm{D}$ atoms with the energy of $215 \mathrm{eV}, 108 \mathrm{eV}$ and $72 \mathrm{eV}$ are 17.2, 9.9, and $9.5 \mathrm{~nm}$, respectively. This means that a large fraction of the incident D ions can penetrate the N-containing surface layer. Thereafter, the thermalized $\mathrm{D}$ atoms can either diffuse inward into the $\mathrm{W}$ bulk or back to the surface where they recombine and get desorbed. In the case of a N-containing layer formed on the top surface, D diffusion outward would be reduced and, therefore, D diffusion inward would be enhanced. Consequently, $\mathrm{N}$ pre-irradiation increases the $\mathrm{D}$ concentration in the near surface as shown in Fig. 5.

In addition, the areal density of the small blisters is significantly increased due to $\mathrm{N}$ pre-irradiation, especially for N500K. It has been reported that the formation of cavities and the following plastic deformation are responsible for the blister formation and growth [35][36], which are triggered by D supersaturation [37]. Since N pre-irradiation enhances the 
D concentration in the near surface (Fig.5 (d)), the areal density of small blisters is increased.

It is worth to note that the $\mathrm{N}$-containing surface layer can be removed by the following D implantation [11]. A typical D implantation lasts $3 \mathrm{~h}$ and we find that this $\mathrm{N}$-containing surface layer can be completely removed by D implantation within $1 \mathrm{~h}$. That is to say, the aforementioned enhanced D inward diffusion due to the N-containing surface layer mainly plays a role at the early stage of the $\mathrm{D}$ exposure. After the $\mathrm{N}$-containing surface layer has been removed, the behavior of the incoming D atoms is similar to the case of Nfree. However, the existing small blisters can significantly reduce the D diffusion into the bulk [30]. As a result, the areal density of the large blisters on the sample with $\mathrm{N}$ pre-irradiation is lower than that for Nfree (Fig. 2). At the same time, we can find a difference of blistering features between the two N pre-irradiated samples (Fig. 3), which could be attributed to different phases of $\mathrm{W}: \mathrm{N}$ layers formed at different $\mathrm{N}$-implantation temperatures [25]. These different $\mathrm{W}: \mathrm{N}$ layers may have different barrier properties for the $\mathrm{D}$ outward diffusion.

For $\mathrm{D} 230 \mathrm{~K}$ and $\mathrm{D} 520 \mathrm{~K}$, the blistering and $\mathrm{D}$ retention is not as significant as that of D370K, while the N pre-irradiation still plays a role. Diffusion and trapping/detrapping are key factors for D behaviors in W, which are strongly dependent on temperature [38][39][40]. At D520K, D atoms mainly ( $70 \%$ ) concentrate within the depth of $130 \mathrm{~nm}$ (Fig. 5) and the total retention is only $\sim 10 \%$ of that at $\mathrm{D} 370 \mathrm{~K}$. This is supposed to be due to the more significant thermal detrapping and enhanced diffusion at $520 \mathrm{~K}$ [41]. As shown in the TDS results (Fig. 6), there are two desorption peaks, $470 \mathrm{~K}$ and $600 \mathrm{~K}$ for D370K, while the $470 \mathrm{~K}$ desorption peak disappears for D520K, indicating a strong detrapping at D520K. As for D230K, the D diffusion and detrapping are both reduced compared to D370K [42]. Therefore, most of the D atoms ( $\sim 90 \%$ ) concentrate in the near surface (within the depth of $400 \mathrm{~nm}$ ), and the total $\mathrm{D}$ retention is much lower than $\mathrm{D} 370 \mathrm{~K}$. However, it can be found that the $\mathrm{N}$ pre-irradiation affects the D depth profiles and D retention for D230K and D520K, and this effect changes a little with $\mathrm{N}$ plasma exposure temperature (Figs. 5 and 8).

\section{Conclusion}

In the present work, we have investigated the effect of exposure temperature on surface blistering and $\mathrm{D}$ retention of $\mathrm{W}$ sequentially exposed to $\mathrm{N}$ and $\mathrm{D}$ plasma.

The D plasma exposure temperature plays an important role on blistering and $\mathrm{D}$ retention. The average blister size is the largest for $370 \mathrm{~K} \mathrm{D}$ exposure as compared to $230 \mathrm{~K}$ and $520 \mathrm{~K}$. When the exposure temperature of D plasma is reduced to $230 \mathrm{~K}$, the average blister size is decreased but the areal density is increased. However, the blistering is suppressed at $520 \mathrm{~K}$. The D depth profiles and TDS spectra show that, the D retention for $370 \mathrm{~K}$ is $\sim 10$ times of those for $230 \mathrm{~K}$ and $520 \mathrm{~K}$.

Moreover, $\mathrm{N}$ pre-irradiation influences the $\mathrm{D}$ behavior in $\mathrm{W}$, which exhibits temperature dependence as well. With $\mathrm{N}$ pre-irradiation, the areal density of blisters is increased, especially for the smaller blisters, which should be ascribed to the increased $\mathrm{D}$ retention in the near surface. This effect is more significant for $500 \mathrm{~K} \mathrm{~N}$ pre-irradiation than $300 \mathrm{~K}$. These phenomena are supposed to be related to the barrier effect of the N-containing surface layer, which reduces the $\mathrm{D}$ outward diffusion and increases the $\mathrm{D}$ inward diffusion accordingly. The temperature dependence can possibly be explained by a change of the phase of W:N layers, which might result in the different barrier effect. 
With a view to ITER and future fusion experiments, the modifications especially the properties and erosion rates of the near-surface layer of $\mathrm{W}$ which is caused by simultaneous $\mathrm{N}$ and D implantation should be investigated. In addition, the effect of surface temperature has to be taken into account. In the future, we plan to perform experiments at increased plasma flux $\left(10^{22} \sim 10^{23} \mathrm{~m}^{-2} \mathrm{~s}^{-1}\right)$ to better simulate conditions in a fusion environment.

\section{Acknowledgments}

This work was supported by the National Nature Science Foundation of China under contract No. 11775015 and a fund from the Science and Technology on Surface Physics and Chemistry Laboratory (No. 02020317). Shaoyang Qin is grateful to be funded by Beihang University for the research visit at IPP-Garching for 3 months. The authors would like to thank Dr. A. Manhard for the technical assistance on the measurements at IPP-Garching.

\section{References}

[1] Philipps V 2011 Tungsten as material for plasma-facing components in fusion devices Journal of Nuclear Materials 415 S2-9

[2] Federici G, Skinner C H, Brooks J N, Coad J P and Grisolia C 2002 Plasma-material Interactions in Current Tokamaks and their Implications for Next-step Fusion Reactors Nuclear Fusion 411967

[3] Pitts R A A, Carpentier S, Escourbiac F, Hirai T, Komarov V, Lisgo S, Kukushkin A S S, Loarte A, Merola M, Sashala Naik A, Mitteau R, Sugihara M, Bazylev B and Stangeby P C C 2013 A full tungsten divertor for ITER: Physics issues and design status Journal of Nuclear Materials 438 S48-56

[4] Kallenbach A, Dux R, Fuchs J C, Fischer R, Geiger B, Giannone L, Herrmann A, Lunt T, Mertens V, Mcdermott R B T-E C on P P, Neu R, Pütterich T, Rathgeber S, Rohde V, Schmid K, Schweinzer J and Treutterer W 2010 Divertor power load feedback with nitrogen seeding in ASDEX Upgrade Plasma Physics and Controlled Fusion 52055002

[5] Kallenbach A, Balden M, Dux R, Eich T, Giroud C, Huber A, Maddison G P P, Mayer M, McCormick K, Neu R, Petrie T W W, Pütterich T, Rapp J, Reinke M L L, Schmid K, Schweinzer J and Wolfe S 2011 Plasma surface interactions in impurity seeded plasmas Journal of Nuclear Materials vol 415 pp S19-26

[6] Oberkofler M, Douai D, Brezinsek S, Coenen J W, Dittmar T, Drenik A, Romanelli S G, Joffrin E, McCormick K, Brix M, Calabro G, Clever M, Giroud C, Kruezi U, Lawson K, Linsmeier C, Martin Rojo A, Meigs A, Marsen S, Neu R, Reinelt M, Sieglin B, Sips G, Stamp $\mathrm{M}$ and Tabares F L 2013 First nitrogen-seeding experiments in JET with the ITER-like Wall Journal of Nuclear Materials 438 S258-61

[7] Rubel M, Philipps V, Marot L, Petersson P, Pospieszczyk A and Schweer B 2011 Nitrogen and neon retention in plasma-facing materials Journal of Nuclear Materials vol 415 pp 223-6

[8] Bereznai M, Tóth Z, Caricato A P, Fernández M, Luches A, Majni G, Mengucci P, Nagy P M, Juhász A and Nánai L 2005 Reactive pulsed laser deposition of thin molybdenum- and tungsten-nitride films Thin Solid Films 473 16-23

[9] Chiu H-T and Chuang S-H 1993 Tungsten nitride thin films prepared by MOCVD Journal of Materials Research 8 1353-60

[10] Meisl G, Schmid K, Encke O, Höschen T, Gao L and Linsmeier C 2014 Implantation and 
erosion of nitrogen in tungsten New Journal of Physics 1693018

[11] Gao L, Jacob W, Meisl G, Schwarz-Selinger T, Höschen T, von Toussaint U and Dürbeck T 2016 Interaction of deuterium plasma with sputter-deposited tungsten nitride films Nuclear Fusion 56016004

[12] Lee H T, Ishida M, Ohtsuka Y and Ueda Y 2014 The influence of nitrogen on deuterium permeation through tungsten Physica Scripta T159 014021

[13] Wang S, Kong X-S S, Wu X, Fang Q F F, Chen J-L L, Luo G-N N and Liu C S S 2015 Effects of nitrogen on hydrogen retention in tungsten: First-principles calculations Journal of Nuclear Materials 459 143-9

[14] Skinner C H, Haasz A A, Alimov V K, Bekris N, Causey R A, Clark R E H, Coad J P, Davis J W, Doerner R P and Mayer M 2008 Recent Advances on Hydrogen Retention in ITER's Plasma-Facing Materials: Beryllium, Carbon, and Tungsten Fusion Science \& Technology 54 891-945

[15] Roth J and Schmid K 2011 Hydrogen in tungsten as plasma-facing material Physica Scripta 201114031

[16] Tanabe T 2014 Review of hydrogen retention in tungsten Physica Scripta 201414044

[17] Shu W M, Isobe K and Yamanishi T 2008 Temperature dependence of blistering and deuterium retention in tungsten exposed to high-flux and low-energy deuterium plasma Fusion Engineering and Design 83 1044-8

[18] Alimov V K K, Tyburska-Püschel B, Lindig S, Hatano Y, Balden M, Roth J, Isobe K, Matsuyama M and Yamanishi T 2012 Temperature dependence of surface morphology and deuterium retention in polycrystalline ITER-grade tungsten exposed to low-energy, high-flux D plasma Journal of Nuclear Materials 420 519-24

[19] Buzi L, Temmerman G De, Unterberg B, Reinhart M, Litnovsky A, Philipps V, Oost G Van and Möller S 2014 Influence of particle flux density and temperature on surface modifications of tungsten and deuterium retention Journal of Nuclear Materials 455 316-9

[20] 't Hoen M H J, Balden M, Manhard A, Mayer M, Elgeti S, Kleyn A W and Zeijlmans van Emmichoven P A 2014 Surface morphology and deuterium retention of tungsten after low- and high-flux deuterium plasma exposure Nuclear Fusion 54083014

[21] Balden M, Manhard A and Elgeti S 2014 Deuterium retention and morphological modifications of the surface in five grades of tungsten after deuterium plasma exposure Journal of Nuclear Materials 452 248-56

[22] Manhard A, Matern G and Balden M 2013 A step-by-step analysis of the polishing process for tungsten specimens Practical Metallography - Praktische Metallographie 50 5-16

[23] Manhard A, Balden M and Elgeti S 2015 Quantitative Microstructure and Defect Density Analysis of Polycrystalline Tungsten Reference Samples after Different Heat Treatments Practical Metallography 52 437-66

[24] Manhard A, Schwarz-Selinger T and Jacob W 2011 Quantification of the deuterium ion fluxes from a plasma source Plasma Sources Science and Technology 20015010

[25] Schmid K, Manhard A, Linsmeier C, Wiltner A, Schwarz-Selinger T, Jacob W and Mandl S 2010 Interaction of nitrogen plasmas with tungsten Nuclear Fusion $\mathbf{5 0} 025006$

[26] Schmid K and von Toussaint U 2012 Statistically sound evaluation of trace element depth profiles by ion beam analysis 281 64-71

[27] Gao L, Jacob W, Wang P, von Toussaint U and Manhard A 2014 Influence of nitrogen 
pre-implantation on deuterium retention in tungsten Physica Scripta T159 014023

[28] Tokunaga K, Baldwin M J, Doerner R P and Noda 2003. Ieee/npss Symposium on N B T-F E 2005 Blister formation and deuterium retention on tungsten irradiated by low energy and high flux deuterium plasma pp 242-5

[29] Gao L, Jacob W, von Toussaint U, Manhard A, Balden M, Schmid K and Schwarz-Selinger T 2017 Deuterium supersaturation in low-energy plasma-loaded tungsten surfaces Nuclear Fusion 57016026

[30] Bauer J, Schwarz-Selinger T, Schmid K, Balden M, Manhard A and von Toussaint U 2017 Influence of near-surface blisters on deuterium transport in tungsten Nuclear Fusion $\mathbf{5 7} 086015$

[31] Gao L 2016 Interaction of Deuterium Plasma with Pre-nitrided Tungsten Surfaces PdD thesis, Ruhr University Bochum (DE). IPP 17/50

[32] Eckstein W 2002 Calculated Sputtering, Reflection and Range Values IPP Report 9/132, Max-Planck-Institut für Plasmaphysik, Garching, Online link: http://hdl.handle.net/11858/00-001M-0000-0027-4522-5

[33] Gao L, Jacob W, Schwarz-Selinger T and Manhard A 2014 Deuterium implantation into tungsten nitride: Negligible diffusion at 300 K Journal of Nuclear Materials 451 352-5

[34] Möller W, Eckstein W and Biersack J P 1988 Tridyn-binary collision simulation of atomic collisions and dynamic composition changes in solids Computer Physics Communications 51 355-68

[35] Haasz A A, Poon M and Davis J W 1999 Effect of ion damage on deuterium trapping in tungsten Journal of Nuclear Materials 266 520-5

[36] Alimov V K, Roth J and Mayer M 2005 Depth distribution of deuterium in single- and polycrystalline tungsten up to depths of several micrometers Journal of Nuclear Materials 337-339 619-23

[37] Condon J B B and Schober T 1993 Hydrogen bubbles in metals vol 207

[38] Ogorodnikova O V., Roth J and Mayer M 2008 Ion-driven deuterium retention in tungsten Journal of Applied Physics 103034902

[39] Franzen P, Garcia-Rosales C, Plank H and Alimov V K 1997 Hydrogen trapping in and release from tungsten: Modeling and comparison with graphite with regard to its use as fusion reactor material Journal of Nuclear Materials 241-243 1082-6

[40] Schmid K, Rieger V and Manhard A 2012 Comparison of hydrogen retention in W and W/Ta alloys Journal of Nuclear Materials 426 247-53

[41] Haasz A A, Davis J W, Poon M and Macaulay-Newcombe R G 1998 Deuterium retention in tungsten for fusion use Journal of Nuclear Materials 258-263 889-95

[42] Poon M, Haasz A A and Davis J W 2008 Modelling deuterium release during thermal desorption of D+-irradiated tungsten Journal of Nuclear Materials 374 390-402 